\title{
Una crítica a la interculturalidad desde la interculturalidad crítica
}

\author{
A Critique of Interculturality from Critical Interculturality \\ Uma crítica à interculturalidade desde a interculturalidade \\ crítica
}

Dra. Lorena Zuchel Lovera* y Mg. Nicole Henríquez Leiva**

\section{RESUMEN:}

El concepto "interculturalidad" ha pasado a convertirse en Chile Palabras clave: en un tema ampliamente incorporado en discursos sociopolíticos, aunque de manera difusa y vacía de significado. Un concepto "de moda", diría Catherine Walsh. Tras estos discursos, podemos evidenciar una afirmación del sistema neoliberal, que reconocimiento, inclusión, neoliberalismo, identidad, praxis se refuerza en la permanente dislocación de voluntades para beneficio del propio neoliberalismo y de su lógica de dominación. A partir de estas ideas, el presente artículo mostrará algunos espacios y formas en los que la interculturalidad se devela de esa manera; a la vez que se ofrecerá, desde la crítica, algunas preguntas que alienten el desafío de "lo inter", revalorando el conflicto, la búsqueda de sus causas, y posibilitando una praxis histórica de liberación.

\section{ABSTRACT:}

The concept of "interculturality" in Chile has become a term widely incorporated within sociopolitical discourse, yet diffu-

Keywords:

recognition,

Chilena. Doctora en Filosofía por la Universidad de Deusto, País Vasco. Licenciada en Filosofía y Bachiller en Filosofía y Humanidades por la Universidad Alberto Hurtado, Santiago de Chile. Académica del Departamento de Estudios Humanísticos, Universidad Técnica Federico Santa María. Contacto: lorena.zuchel@usm.cl ORCID: https://orcid.org/0000-0002-4793-595X

** Chilena. Magíster en Filosofía Contemporánea por la Universidad de Valparaíso, Chile. Licenciada en Filosofía y Educación y Pedagogía en Filosofía por la Universidad de Valparaíso, Chile. Profesora de filosofía en Colegio Curimón. Contacto: henriquezleivanicole@gmail.com ORCID: https://orcid.org/0000-0002-1741-8855 
sely and void of meaning. A "trendy" concept, Catherine Walsh would say. Through these discourses, we can see an affirmation of the neoliberal system, which is reinforced in the permanent dislocation of wills for the benefit of neoliberalism itself and its logic of domination. Based on these ideas, the present article will show some of the spaces and forms in which interculturality is revealed in this way, while critically offering some questions to challenge "the inter," revaluing conflict, the search for its causes, and enabling a historical praxis of liberation.

\section{RESUMO:}

O conceito "interculturalidade" passou a ser um tema amplamente incorporado em discursos sócio-políticos no Chile, ainda que de maneira difusa e de significado vazio. Um conceito "de moda", diria Catherine Walsh. Após esses discursos, podemos evidenciar uma afirmação do sistema neoliberal, que se reforça no permanente deslocamento de vontades em benefício do próprio neoliberalismo e de sua lógica de dominação. A partir destas ideias, o presente artigo mostrará alguns espaços e formas nos quais a interculturalidade se revela dessa maneira; ao mesmo tempo que serão oferecidas, desde a crítica, algumas perguntas que incentivem o desafio do "inter", revalorizando o conflito, a busca de suas causas e possibilitando uma práxis histórica de libertação. inclusion, neoliberalism, identity, praxis

Palavras-chave: reconhecimento, inclusão, neoliberalismo, identidade, práxis 


\section{Introducción}

La interculturalidad como estrategia de coexistencia en la diversidad cultural continúa siendo, a más de veinte años de su aparición en las ciencias sociales latinoamericanas, un horizonte que tiende a alejarse a cada paso que se avanza. La violencia fáctica y simbólica se ha impuesto como el principal modo de relación interpersonal, obstaculizando la asunción de la interculturalidad y cerrando con ello las puertas a una cultura de la paz que torne posible la justicia social, económica, política y la superación efectiva de las problemáticas del subdesarrollo" (Donoso, Contreras, Cubillos y Aravena).

Lo que hoy se ha tendido a llamar "multiculturalidad" da cuenta básicamente de un fenómeno que salta a la vista: somos diversos. Ya porque los procesos migratorios se han complejizado en las últimas décadas (Di Castro), ya porque estos han reforzado la voz silenciada de minorías presentes desde siempre en los distintos países, ya porque esas minorías aparecen de pronto en tal cantidad que hoy se pueden contar efectivamente como mayorías (Van Cott 2000), entre otras razones, es que hoy vemos múltiples espacios dedicados a resolver las crecientes complicaciones que estos procesos parecieran estar provocando a la "estabilidad" de los Estados ${ }^{1}$. Como se puede adelantar rápidamente, las razones que incitan estas prácticas —según desde dónde se miren - podrían ser beneficiosas o no; pero justamente eso, que haya un lado y otro (y muchos más, por cierto) desde los que mirar, defender, opinar, es que hoy parece ser suficiente para calificar estos procesos como "problemáticos". Entonces, no cualquier diálogo ni cualquier sufijo es adecuado para confrontar los problemas, aunque sí para "resolverlos", hacerlos desaparecer o más bien homogenizar nuevamente los espacios - si esto se quisiera ${ }^{2}-$. Una forma de confron-

\footnotetext{
1 Se quiere acentuar aquí la complicación que se comunica, desde algunas grandes potencias, como los EE.UU. u otros europeos, sobre estos fenómenos, esbozados frecuentemente como "problemas". Véase sobre esto en The economist (2004): "Diversity and development", 15 de julio de 2004. Disponible en: http://www.economist.com/ node/2926697

2 Es menester notar que en 2004 el concepto de diversidad fue reconocido como requisito mínimo del informe anual sobre Desarrollo Humano del PNUD, sobre bienestar social y económico. La idea en torno a este informe es que hoy todos los países son sociedades multiculturales y, entonces, "la diversidad cultural ha llegado para quedarse, y crecer". PNUD. Informe sobre desarrollo humano 2004. La libertad cultural en el mun-
} 
tarlos, ofrecida desde lugares periféricos, principalmente indígenas y afroamericanos, en las últimas décadas, ha sido desde propuestas interculturales. Estas son teorías que promueven el reconocimiento no totalizador de las diversidades existentes; mas hoy, sus términos y categorías han sido apropiados por el discurso-que-resuelve de los gobiernos neoliberales, y, entonces, los escuchamos y leemos vaciados de significado.

Desde aquí podemos esbozar una hipótesis que intentaremos confirmar en este trabajo, a saber: que existe hoy una interculturalidad funcional al sistema neoliberal, que se ha apropiado de vocablos que, por décadas, han defendido las demandas de movimientos sociales críticos. Para esto nos basaremos en informes de organizaciones latinoamericanas e internacionales, como en diversos textos de autores que, desde una perspectiva interdisciplinar, han esbozado elementos críticos que podríamos señalar como una actualización de las teorías del reconocimiento (Honneth, Salas) o de las teorías críticas que caracterizaron el trabajo de intelectuales de las humanidades y de las ciencias sociales que, desde la primera mitad del siglo XX, en medio de una Europa convulsionada, realizaron fuertes críticas a la normalidad política de facto y a las teorías científicas predominantes.

\section{Un ejemplo real a modo de "cuento corto"}

A fines de los ochenta, en Ecuador, la interculturalidad se mostró como un principio político e ideológico fundamental del movimiento indígena y afroecuatoriano. En tiempo de kaıpïo (Zuchel 2017a 35), podríamos decir, en ese tiempo de posibilidades que emerge tras los ya 500 años de colonización, surge una presión social tal que lleva a que el gobierno ecuatoriano la asuma como su propia demanda, y la incorpore a la Reforma Constitucional de 1998 (luego de una aproximación educativa de estos esfuerzos en años anteriores). Desde entonces, este país se reconoce como intercultural, otorgando quince derechos a los pueblos indígenas y afroecuatorianos.

do diverso de hoy, 2. Disponible en http://hdr.undp.org/sites/default/files/hdr_2004_ es.pdf 
Cumpliéndose una década de la declaración de estos derechos, unos detallados informes ${ }^{3}$, desarrollados por diversas instituciones observadoras de Derechos Humanos, indicaron que el reconocimiento que otorgó la constitución del $98^{4}$ a la situación social, económica y cultural de estos pueblos, no logró su cometido, sino, al contrario, una precarización (CONAIE 9)5. En múltiples informes, la Confederación de Nacionalidades Indígenas del Ecuador, CONAIE, manifestaba que los derechos promulgados eran incompatibles con el modelo económico y social vigente en el Ecuador; este modelo era identificado como "neoliberal".

\section{Del ABC}

En El ABC del neoliberalismo, su editora, Mary Luz Estupiñán, arguye que el neoliberalismo no es un simple programa, grupo de medidas o una ideología más, sino, siguiendo a Michel Foucault, una "racionalidad política" (Estupiñán 2017 9). Esto supone una organización de entramados, andamiajes, de tal forma presentados que delinean subjetividades y prácticas con intenciones precisamente neoliberales. Para ello, se van adaptando discursos, adecuando conceptos, de modo de ir ampliando sus posibilidades, con el propósito de hacer sentir a las personas cómodas y seguras. Se dispone una suerte de "lenguaje" que se vuelve lugar común entre los ciudadanos, de manera que se naturaliza en sus vocabularios, y más que eso, en su vida cotidiana (Estupiñán 2017 11). Así es como el neoliberalismo permite que ciertos conceptos suyos parezcan "obvios", necesarios de defen-

\footnotetext{
“En esta década (1998-2008) se ha acentuado la desposesión de los territorios de los pueblos indígenas, y se ha ejercido una mayor violencia, con matices que van desde la criminalización a las protestas y resistencias sociales de las comunidades y pueblos indígenas, hasta la geopolítica del Plan Colombia y de los megaproyectos productivistas y extractivistas contenidos en la iniciativa IIRSA". Ver CONAIE (13).

${ }_{4} \quad$ En 2008 se recogen otras propuestas de los pueblos indígenas, que incluyen la plurinacionalidad del Estado, el Derecho Humano al agua, el Buen Vivir, entre otras.

5 Este documento luego es refrendado por un informe alternativo de FLACSO-Ecuador, en el que se monitorean cinco ejes temáticos: Territorialidad; Recursos naturales y consulta previa; Derecho indígena; Trabajo y salud, y Educación y participación. Otro documento importante es el Informe Regional del Observatorio DESC Amazonía, editado en diciembre de 2006. Se trata del documento de "Situación de los Derechos Económicos, Sociales y Culturales en la Región Amazónica de los Países andino-Amazónicos". En ese sentido, el observatorio analiza la situación de los Derechos Humanos en la región bajo la existencia de tres procesos concomitantes y correlacionados: el modelo extractivista; la violencia estructural y la colonización permanente.
} 
der, pues habría una identificación entre estos y aquellos; mas ese lugar común, con su racionalidad común, ha ido ampliando sus fronteras, y la manera más astuta y eficaz para hacerlo ha sido a través del lenguaje. Es así como encontramos ciertas palabras repetidas una y otra vez en los medios de comunicación y como términos mínimos para focalizar cada estrategia institucional. En este caso, vocablos que refuerzan la imagen de un sujeto neoliberal que se articula en una identidad social que la siente suya, o, peor aún, naturalmente suya. Podemos sostener, con el filósofo esloveno Slavoj Zizek, que "en el capitalismo global de la actualidad opera una lógica multicultural que incorpora la diferencia mientras que la neutraliza y la vacía de su significado efectivo" (Zizek 29). Este vacío sería precisamente lo que convoca la crítica del concepto de "interculturalidad" que hasta hace poco se defendía en Ecuador, la crítica a la imposición de un entramado de posibilidades que, a la vez que ofrece "seguridad", va desarticulando confianzas y trabajos colaborativos, va trocando unas determinadas praxis por otras.

\section{Otro ejemplo problemático}

Si hacemos el ejercicio de buscar en internet noticias chilenas con la palabra "interculturalidad", nos damos cuenta de que son tantas las entradas como variadas entre sí. Por nombrar unas del último año, podemos identificar las siguientes: "En La Araucanía se inauguró la primera Oficina Nacional de Pueblos Indígenas del Instituto Nacional de la Juventud" (Radio Biobío, 27 de abril de 2017): "Con el objetivo de perfilar políticas e investigaciones, pertinentes al proceso migratorio que vive la Región de Antofagasta, junto con generar proyectos de largo y corto plazo, que favorezcan la integración de las nuevas comunidades con el sector público, se desarrolló en la UA el Primer Consejo Ciudadano de Interculturalidad del 2017" (Universidad de Antofagasta, 18 de abril de 2017). "La Feria del Libro Independiente de Valparaíso inicia su trabajo de inclusión contando con intérpretes de lengua de señas para integrar a diversos actores culturales de nuestra comunidad" (El Martutino, 18 de abril de 2017). "Concejal de Osorno solicita instalación de señalética municipal en che zungun por interculturalidad" (Radio Biobío, 14 de abril de 2017). "USS abrirá el primer posgrado sobre integración de inmigrantes a colegios y jardines" (El Dínamo, 7 de marzo de 2017). "La cons- 
trucción de dos hospitales interculturales entró en tierra derecha este 2017" (El Ciudadano, 16 de febrero de 2017).

Dado lo anterior, podríamos preguntar qué problemas habría con estas políticas - con buenas intenciones, quizás- que dan para subtitular este apartado como "problemático". Podemos volver al El ABC del neoliberalismo y darnos cuenta de que lo que está detrás de estas "políticas" es, precisamente, esa forma de gobernanza que apela a todos los grupos de interés, esa que nos da comodidad (y seguridad, por cierto). Y por eso vemos cruces entre organizaciones públicas, privadas o de la sociedad civil (Estupiñán 17), moviendo actores de aquí para allá, preocupados y ocupados, haciendo parecer excelente un juego democrático de inclusión que, como juego, "se la juega" por la diversidad, promoviendo a estos grupos (mapuches, huilliches, aymaras, haitianos o inmigrantes, en general) como grupos de atención, particularismos externos a lo nacional-estatal.

No son solo las relaciones de poder que se desdibujan en esta construcción discursiva y cognitiva de lo que podemos denominar el multipluriculturalismo oficial, sino también la manera como las categorías etno-racializadas han servido (y siguen sirviendo) para construir y perpetuar el peso de la colonialidad y reestructurar el colonialismo, y para lograr los intereses del capitalismo global. De esta manera, la memoria se borra y es reemplazada, de ahora en adelante, por la nueva diversidad en la cual los grupos étnicos coexisten pacíficamente, hasta con supuesta "voz" en el gobierno y en el Congreso Nacional, o al frente de los organismos multilaterales y de las empresas transnacionales (Walsh 2002 121).

Con todo, pensadores interculturales, como Dina Picotti, Raúl Fornet Betancourt, Ricardo Salas, Silvia Rivera Cusicanqui, Catherine Walsh, entre otros, critican esta forma de consulta y participación en cuanto perpetuidad de asimetrías del poder existente entre los participantes (hay que decir que estos titulares de prensa son los mismos de los últimos años, que se leen en Ecuador y en Chile), con el mismo modus operandi, que es el de crear una "diversidad en la unidad" desde procesos descendentes, que descansan sobre todo en una técnica de merchandising, es decir, como una estrategia de marketing masiva que quiera llamar la atención a favor de incrementar la rentabilidad de un producto. El producto en cuestión es una forma de gobernanza, 
diversa y dinámica, capaz de enfrentar "eficientemente" los desafíos que hoy se imponen (Estupiñán 216); la estrategia es la preocupación (inclusiva) por "buenas prácticas" a escala global. En el caso que aquí se analiza, la preocupación por la inclusión de una identidad tradicional que niega la existencia de la diferencia colonial. Sobre esto, Walsh refrenda con el afroecuatoriano Óscar Chalá que la lucha intercultural "no es sobre la etnicidad o la cultura en sí, sino sobre la extrema desigualdad" (Walsh 2002 126).

\section{El problema de cierta interculturalidad}

La filósofa ecuatoriana Catherine Walsh comenta - tal como esbozábamos en un comienzo- que la interculturalidad en su país se ha venido convirtiendo en el último tiempo en un tema de moda (Walsh 2009 1). En efecto, después del 11 de septiembre de 2011 se ha debido considerar con mayor atención la coexistencia de diversas acepciones sobre interculturalidad; pues, si bien en Ecuador el concepto surge - como en otros países latinoamericanos y africanos- en tanto intención de denuncia y resistencia de los pueblos originarios ante la irrupción de la hegemonía monocultural; hoy, ya presente en la jerga estatal - constitucional—, su contenido invoca integración, apelando más a una sociedad de los iguales que a una sociedad igualitaria.

Esta alteración puede entenderse desde la necesidad de neutralizar las diferencias que, en el caso de este concepto, no solo dificultaría el orden neoliberal, sino que representaría un conflicto en sí mismo (un des-orden) en cuanto praxis histórica de liberación; esto es, como construcción constante de un proceso político y social identitario, enmarcado en una variedad de posiciones dinámicas, individuales y colectivas, muchas veces encontradas y sobre todo abiertas (Walsh 2009 13-14). Esta apreciación es la que hace de la lucha intercultural del kaıрïo una lucha de "movimientos" indígenas y afroecuatorianos (en este caso), y no de grupos clausurados, o de comunidades - en el sentido inmunitario que se cierra a lo propio, en palabras de Esposito-, que se entrecruzan con la propia acepción indígena de poder que precisamente quiso ofrecer en los noventa "un proyecto políticoepistémico de la interculturalidad, de la construcción de una 'democracia de cosmovisiones diversas"' (Walsh 2009 6). Esta nueva forma de entender la democracia, ofrecida por los movimientos indígenas, 
obedece a una comprensión del término "poder" que implica "yachai, sabiduría; ricsina, conocimiento; ushai, saber ejecutar; pactana, saber alcanzar; muskui, la visión del futuro" (Walsh 2002 5). Como vemos, esta quíntuple acepción contiene conceptos espacio-temporales que harían imposible una localización de la verdad, lo que sería inconveniente para un "orden" de carácter totalizante. Insiste en esto - nos dice Walsh - el intelectual y político indígena ecuatoriano Carlos Viteri, al referir que "el 'poder', entendido sobre estos códigos, se convierte en un concepto en permanente construcción, cuya relación dialéctica con la vida social supone el equilibrio, la armonía, es decir, la convivencia" (Ibíd.). La propuesta, entonces, que presentaron movimientos indígenas, desde las terminologías antes descritas, proponía incorporar en un nuevo proyecto de Estado:

... la sabiduría para conducir a los pueblos sobre programas y propuestas claras; conocimiento para entender la compleja y diversa geografía humana, para propiciar el encuentro; saber ejecutar para no caer en improvisaciones [...]; saber alcanzar para perseverar en el cumplimiento del cometido; y visión de futuro para franquear el inmediatismo y ser sectores de verdaderos procesos de cambio (Ibid.).

Pero esta comprensión del poder, que defiende a la lucha intercultural como una propuesta reivindicativa y constructiva, no solo no fue considerada, sino que fue vaciada de contenido, a la vez que representada como una fórmula para la tolerancia hacia unas culturas estereotipadas, esencialistas y estáticas. La denuncia que hacen los movimientos indígenas ecuatorianos es precisamente aquella que ubica las reformas constitucionales como parte de la nueva lógica del capitalismo multinacional, desdibujando las relaciones de poder y ocultando la colonialidad. Lo que pasa aquí, dice Walsh, es que:

... mientras el Estado reconoce la diversidad étnica y otorga derechos específicos, el hecho de reducirlo a una salida solo para los grupos étnicos limita la esfera del cambio a la particularidad étnica (promoviendo así un cierto tipo de relativismo cultural) "que supuestamente puede lograrse sin transformaciones sustanciales del Estado-nación". Esta táctica de reconocer la diversidad incorporándola dentro del aparato estatal y, a la vez, promoviéndola como particularismos externos a lo nacional-estatal no está limitada al 
Ecuador; por el contrario, es representativa de las nuevas formas de universalidad promovidas por el discurso y las políticas de la globalización neoliberal (Ibíd.).

En un texto escrito por Charles Hale y Rosamel Millamán: "Cultural Agency and Political Struggle in the Era of Indio Permitido", se ocupa el término "indio permitido", rescatado de Silvia Rivera Cusicanqui para referirse precisamente a la permisión de cierto tipo de diversidad. Este término, comenta Hale, fue expresado con "frustración y desesperación" en un taller sobre derechos culturales y democratización en América Latina, en el que la activista boliviana exponía: "Tenemos que encontrar, dijo Rivera, un método para describir cómo los gobiernos utilizan los derechos culturales para dividir y neutralizar a los movimientos indígenas" (Hale 4). No es novedad que la palabra indio tenga una serie de connotaciones despectivas; varios trabajos sobre estereotipos resaltan frases como "hacer el indio" (Nikleva 2012 997) o "no seas indio" (Cojtí 35), y Hale tampoco niega esa dificultad; sin embargo, precisamente por eso es que retoma las palabras airadas de Rivera Cusicanqui para levantar una categoría incómoda. Pues claro, si decir "indio" parece ser la mayor de las veces un adjetivo negativo, ¿cómo se permite lo negativo? Esta aporía representa de buena manera lo que pasa; y lo que pasa -insisten - es que, a fin de cuentas, solo se permite la afección para algunos y de un cierto modo, de manera que no se llegue a modificar, a dañar el escenario beneficioso de los pocos de siempre:

El riesgo para los movimientos indígenas que se ubican dentro de los parámetros preestablecidos de estas políticas, es que los beneficios se dirigen a un grupo minoritario de actores indígenas y provoca la exclusión de los demás; es más: esas políticas transmiten un mensaje implícito de que está bien que los indígenas gocen de ciertos derechos, siempre y cuando dejen de exigir los demás (Hale 5)

En este mismo texto, Hale rescata una cuestión del Abecé que aquí hemos querido mostrar, y es que el lenguaje juega un papel central en las reglas del reconocimiento de la racionalidad neoliberal, pues hay una serie de categorías que el "indio permitido" asume, porque de otra manera no cabe, no juega, se excluye o no se permite. Hay un otro, entonces, que no participa y que es efectivamente un "otro", abandonado en la pobreza y en la exclusión social: "Los que ocupan la 
categoría del 'indio permitido' tienen que demostrar constantemente que están por encima de estas características culturales 'racializadas' de los 'otros', y al insistir de esta manera, apoyan y refuerzan la división" (Ibíd.). Mencionar al "otro" citado por Hale es precisamente lo que aquí nos congrega: el examen de esa voluntad de reconocimiento. Con esto queremos decir que, así como hay una insistencia hoy en diversas políticas de inclusión llamadas "interculturales", también hay voces críticas que insisten en esa posición como de "falsas voluntades". Pues, más que reconocimiento por el "indio", ha habido una intensificación de la promoción de una identidad esencializada, que no se corresponde con la realidad compleja de este "otro", lo que ha traído división y sometimiento. Y, por otro lado, porque ese reconocimiento ha insistido en la posibilidad de, quizá, un imposible: la comprensión del otro como otro.

\section{Una interculturalidad crítica y (¿un reconocimiento?) posible}

Podemos abordar dos asuntos. El primero tiene relación con una crítica de pensadores de la interculturalidad latinoamericana acerca de lo que se dice y quiere hacerse con una cierta "identidad" de los pueblos indígenas, inmigrantes entre "otros". El segundo se vincula con una crítica a la interculturalidad como momento de reconocimiento comprensivo de un "otro".

\subsection{Critica a una interculturalidad funcional}

En Sociología de la imagen. Miradas ch'ixi desde la historia andina, Rivera Cusicanqui muestra la posibilidad de un método intercultural que quiera poner énfasis en el movimiento. Quizá "movimiento" sea una palabra que la describe bien a ella y a su trabajo, pero sobre todo que describe bien la posición que desenmascara identidades estereotipadas sobre aquello que serían y no serían los indios. Pues, en efecto, no solo intenta visibilizar la vulnerable posición de la región, tal como lo muestra una idea de "desarrollo" que ella prefiere llamar "miserabilismo", sino también presenta a los indios como identidades abiertas en una praxis en permanente proceso de dislocación-posición. Para esto utiliza imágenes - siendo incluso, por momentos, más proclive a los trabajos audiovisuales - con tal de exponer tanto "caminar" sobre 
contradicciones, revolcando el tiempo con las armas de lo paradójico, y también de lo olvidado (Rivera Cusicanqui 2015b 30). La autora, con la exposición de pequeños relatos y fragmentos, revela los procesos de nacionalización de lo boliviano y de su historia, incluyendo narraciones de la construcción de un ciudadano homogéneo que "ha sido 'liberado' por la revolución, y el Álbum lo transforma en ornamento de una nueva cultura hegemónica que lo somete a los supuestos conductores de este gran hecho colectivo" (Id. 128). Se refiere entonces a lo que antes ya habíamos esbozado como "indio permitido", personaje creado por y para un sistema de dominación. Un indio certificado -agrega en otro momento-y, entonces, neutralizado (Rivera Cusicanqui 2015a 58). Este indio ahora es refrendado en otras latitudes del planeta a través de lo que el neoliberalismo ya ha aprehendido de la interculturalidad, de sus conceptos y sus efectos. Esta nueva localización de la interculturalidad ha sido llamada por otros pensadores como "interculturalidad funcional". Esto implica un uso de ciertas ideas para la propia conveniencia discursiva y totalizadora, con el propósito de asumir discursos, imágenes e ideas de un lado y de otro, sin importar de quién y de dónde sean, con tal de cumplir sus objetivos. A esto Riviera Cusicanqui lo llama "travestismo de las elites":

En Bolivia puede verse esta suerte de travestismo de las élites, que parecen recoger de buen grado el desafío de la insurgencia indígena, pero que al cabo de un tiempo acaban expropiando y deformando sus demandas, hasta convertirlas en dispositivos de una nueva ingeniería estatal (Rivera Cusicanqui 2015a 52).

Interculturalidad funcional es, para el filósofo peruano, Fidel Tubino una actitud "neo-liberal", que intenta destacar ciertas cualidades de los "otros", para garantizar la estabilidad de la praxis vigente (Tubino 2018a 5). Se trataría de una asimilación de ciertos rasgos culturales en beneficio de la cultura dominante, que él llama "cultura diurna" (Tubino 2018b 15). Diurna, porque funciona a plena luz del día, a través de las funciones públicas, de la administración de justicia, de la salud pública y de la educación, entre otras, en contraposición de las "culturas nocturnas" (en plural), que no se ven, que parecen no existir, porque en el fondo son rechazadas, y no oficializadas. Esta dinámica, relatada por Tubino como un aspecto oscuro o invisible de ciertas culturas, muestra también lo que la interculturalidad funcional tiende a esconder: la 
pobreza estructural que mantiene la subalternidad. Para Tubino, como para Walsh, este es el principal problema de la interculturalidad funcional, pues básicamente se ha esbozado para no cambiar las estructuras poscoloniales vigentes (Tubino 2018a 6); pero sin redistribución no hay reconocimiento. Así lo expresa también Nancy Fraser:

... la identidad de grupo sustituye a los intereses de clase como mecanismo principal de movilización política. La dominación cultural reemplaza a la explotación como injusticia fundamental. Y el reconocimiento cultural desplaza a la redistribución socioeconómica como remedio a la injusticia y objetivo de la lucha política (Fraser 17).

Esta lógica funcional es una nueva estrategia de dominación contemporánea, que actúa resignificando aquellos gestos que, desde antaño, han caracterizado praxis fronterizas con el fin de disminuir sus costos y ampliar sus posibilidades. Las apropiaciones son ya no solo teológicas, como hiciera un incipiente capitalismo, sino ahora también de culturas ancestrales, ofrecidas como posibilidades novedosas que no solo sirven para ampliar vocablos en sus discursos, esto es, los andamiajes del aparato, sino también, como bienes de consumo.

\subsection{Crítica a una interculturalidad comprensiva}

Como hemos dicho, parece ser parte del proceso de inclusión o de permisión del "otro" un tipo de reconocimiento que termina asociando una cierta identidad de este "otro" con ciertos rasgos característicos del mismo. Pues bien, esto se puede explicar desde una interculturalidad funcional - que está de moda-, que no deja al azar rasgos a destacar, sino que los elije muy cuidadosamente para perfilar al otro según su propia conveniencia. No obstante, toca preguntarse si esa práctica, ya denunciada, no sería también un problema inherente a cualquier tipo de reconocimiento. Es decir, si no sería una reducción que hacemos cada vez que nos proponemos siquiera conocer y acercarnos al "otro".

Esto ya ha sido trabajado por pensadores como Emmanuel Levinás en De otro modo que ser, al expresar el reconocimiento del Otro en reivindicación del mismo, y refutando en el acto la posibilidad de comprensión de otro como otro (Levinás), denunciando así la imposibilidad ética de un reconocimiento que quiera "comprender" al otro como se quisiera. Luego, el otro, su rostro, es al mismo tiempo desafío de la 
ética, sí, pero también es lugar de la violencia (Campos). Este abordaje fenomenológico, que se puede comprender más radicalmente con Husserl y Derrida, es una cuestión que debe asumir una interculturalidad crítica que no quiera excluir al otro, pero que tampoco desee caer en la ingenuidad de un movimiento de homogeneización que identifica distinguiendo: lo que caracteriza al movimiento neoliberal. Dado lo anterior, creemos que hay una manera de abordar esta complejidad en las propias teorías interculturales latinoamericanas, más precisamente en aquellas que destacan la praxis como momento fundamental de una ética de la liberación, tal como la que aquí perseguimos.

\section{A modo de conclusión: una interculturalidad crítica desde una praxis histórica de liberación}

Hay varias cuestiones que podemos destacar como cierre de este ensayo. Entre ellas, que la diversidad es un hecho. Así lo dicen informes internacionales que, incluso, nos obligan a realizar cada cierto tiempo reportes de avances en materia de reconocimiento, y lo dicen diariamente, de igual manera que los noticiarios e, incluso, nuestras calles. En este sentido, entre las formas como se ha abordado la multiculturalidad destaca una serie de políticas públicas que muestra una cierta voluntad de inclusión, esto es, de incorporar a ese "otro" a las dinámicas de los diversos países, a la norma poblacional deseada. Pero aún de manera engañosa, pues existen diferencias fundamentales entre nacionales y extranjeros, "al punto de tener estatutos jurídicos diferenciados” (Bassa 114). Entonces, hay aquí una primera cuestión que afirmar: inclusión no es lo mismo que interculturalidad, pues la interculturalidad no busca incorporar a los otros a un espacio sin más, sino que busca que esos otros puedan tener garantías como cualquiera. $\mathrm{Y}$ para que eso ocurra, la interculturalidad busca que esos otros puedan participar en la construcción y reconstrucción de lugares en los que todos puedan reconocerse.

Al observar diversos usos del concepto de "interculturalidad", se puede detectar una clara presencia del neoliberalismo como racionalidad macropolítica, que modula subjetividades con prácticas gubernamentales que rebasan sus propios límites desde una serie de articulaciones micropolíticas, adecuando incluso conceptos para generar un clima de cotidianidad en el que todos puedan sentirse parte y a gusto. 
Es así como encontramos tránsitos de una idea de "multiculturalidad" a otra idea de "interculturalidad", generando apropiaciones de ideas -y pugnas - anteriores a "la moda" que hoy ha generado el fenómeno de la migración.

La interculturalidad se comenzó a construir como principio político e ideológico a través de las luchas de los movimientos indígenas y afroamericanos por lo menos desde inicios de los años 90 (Walsh 2002 115), poniendo énfasis en reformas constitucionales que, en variados países latinoamericanos, incluso en aquellos con menos presencia de indígenas y de inmigración ${ }^{6}$, han dado sus frutos. No obstante, la presencia del concepto en países neoliberalizados ha dado pie también a diferentes interpretaciones, lo que hoy pensadores interculturales acusan, y aquí hemos querido mostrar. Esto es, una interculturalidad funcional, que insiste en ciertas identificaciones culturales esencialistas, cerradas, que resaltan además ciertas caracterologías del otro a conveniencia de los propios propósitos del sistema.

Al margen de estas denuncias, es complejo realizar una aproximación a una dinámica del reconocimiento desde una perspectiva crítica filosófica sin caer en la aporía de la alteridad. Por ello, es menester asegurarnos de no caer en la utilización que se da sutil, pero groseramente en el neoliberalismo a través de identificaciones categoriales que hemos visto repetidamente desde la colonia. Pero, aun así, al margen de las dinámicas de dominación eurocéntricas y neoliberales, es preciso cuestionar nuestras propias prácticas e intenciones, para asegurar que, dentro de nuestros acercamientos hacia el otro, no se den las mismas dinámicas. Una interculturalidad crítica debe conocer estas dificultades y localizar una metodología que pueda descentrarse lo suficientemente como para posibilitar una interculturalidad que no quiera apropiarse del desventajado para hablar en su nombre, sino que permita su presencia relacional con todo lo que está siendo y pueda llegar a ser, desde los agenciamientos moleculares que caracterizan su incómoda presencia. La incomodidad relatada es síntoma de la dominación de un sistema que impone una forma de ser. La ventura de estos "mo-

Ver el caso de El Salvador, en Zuchel, L. y Samour, H. "Elementos filosóficos para una interculturalidad crítica. Aportes desde la filosofía del reconocimiento de Raúl Fornet Betancourt, y de la filosofía de la realidad histórica de Ignacio Ellacuría. Pronto a publicarse. 
vimientos", tan abiertos como cualquiera, es a la vez fuerza de transformación, capaz de unirse con otros en praxis históricas concretas (Fornet Betancourt 2001 50) sobre una dinámica de "disposición" que deja al otro in-definido desde nuestra posición. Empero, como insiste Raúl Fornet Betancourt, que esta "in-definición nada tenga que ver con la indiferencia" (Id. 51). De aquí es que sea menester recuperar una interculturalidad que se teja desde una praxis inmanente, que en la cotidianidad pueda avanzar en la denuncia de aquellos procesos de sometimiento micropolíticos que formulan realidades históricas. Esta praxis que hemos nombrado la pensamos en la definición que ha dado Ignacio Ellacuría, entendida en el dinamismo de la realidad como proceso histórico que es productivo y transformativo (Ellacuría 472). En Ecuador, el proyecto plurinacional todavía no se ha logrado, pero los desafíos propuestos por grupos que surgieron de praxis micropolíticas han logrado situar la temática en diversas instituciones, permitiendo la molestia - que a veces es mejor forma de reconocimiento que la invisibilización- que da esperanza a una cada vez más activa interpelación del proyecto neoliberal, que todavía no logra instalarse por completo.

En Chile, por lo que se lee en la prensa, la posibilidad de un "proceso intercultural" (como quizá sería mejor llamarle) está todavía ausente. De caminar hacia allá se requeriría una transformación que ponga en continuo cuestionamiento las estrategias de marketing que hoy sostienen la moda, intervenciones y luchas en torno a otras formas de gobierno, desde los movimientos sociales (indígenas, migrantes, feministas, etc.) que posibilitan un espacio en el que todos puedan ser reconocidos, interrumpiendo el hábito y transformándolo.

\section{Bibliografía}

Bassa, Jaime. "El ejercicio de los derechos de las personas migrantes ante una vieja institucionalidad chilena". Contrabandos. Escrituras y políticas en la frontera entre Bolivia y Chile. eds. A. Ajens, A. Fielbaum y L. Zuchel. Viña del Mar: Communes, 2017. 99-125.

Campos, Valeria. Violencia y fenomenología. Derrida, entre Husserl y Levinas. Valparaíso: Metales Pesados, 2017.

Cojlí, Waq'j Q'anil Demetrio. "El proceso de mayanización y el papel de la educación escolar (Análisis documental)”. Mayanización 
y vida cotidiana. La ideología multicultural en la sociedad guatemalteca. eds. S. Bastos y A. Cumes. Guatemala: Flacso, 2007. 9-61.

Comunicaciones UA: "Consejo ciudadano busca crear políticas migratorias". [Acceso 25 de enero de 2018], 2017. Disponible en: http://www.comunicacionesua.cl/2017/04/18/consejo-ciudadano-busca-crear-politicas-migratorias/

CONAIE. Ecuador. "Derechos colectivos de los pueblos y nacionalidades. Evaluación de una década 1998-2008”, 2009. [Acceso 27 de enero de 2018]. Disponible en: http://www.ipesderechoshumanos.org/pdf/proyecto-implemdchos-dchos-colectivos-ecuador-1998-2008.pdf

Di Castro, Elisabetta. "Migración internacional y derechos fundamentales". Arbor 188.755 (2012): 503-511.

Dimitrinka, Georgíeva Níkleva. "Educación para la convivencia intercultural”. Arbor 188.757 (2012): 991-999.

Donoso Romo, Andrés., Rafael Contreras Mühlenbrock, Leonardo Cubillos Puelma, Luis Aravena Aragón. "Interculturalidad y políticas públicas en educación superior. Reflexiones desde Santiago de Chile". Estudios Pedagógicos XXXII. 1 (2006): 21-31. [Acceso 25 de enero de 2018]. Disponible en: http://www.scielo.cl/scielo.php?script=sci_arttext\&pid $=$ S0718-07052006000100002

Ellacuría, Ignacio. Filosofía de la realidad histórica. San Salvador: UCA editores, 1990.

Espósito, Roberto. Inmunitas. Protección y negación de la vida. Buenos Aires: Amorrortu Editores, 2005.

Estupiñán, Mary Luz. El abc del neoliberalismo. Viña del Mar: Communes, 2017.

Fornet Betancourt, Raúl. Transformación intercultural de la filosofía. Barcelona: Desclée de Brouwer, 2001.

Fraser, Nancy. Iustitia Interrupta Reflexiones críticas desde la posición "postsocialista". Bogotá: Siglo del Hombre Editores y Universidad de Los Andes, 1997.

Hale, Charles. "El protagonismo indígena, las políticas estatales y el nuevo racismo en la época del 'indio permitido'. Ponencia para la conferencia". Construyendo la paz: Guatemala desde 
un enfoque comparado. Minugua: Misión de Verificación de las Naciones Unidas en Guatemala, 2004.

Hale, C. y Millaman, R. "Cultural Agency and Political Struggle in the Era of Indio Permitido". Cultural Agency in the Americas D. Sommer (ed.). Durham, NC: Duke University Press, 2005. 281-3014.

Honneth, Axel. Kampf um Anerkennung-Zur moralischen Grammatik sozialer Konflikte. Frankfurt: Suhrkamp, 1992 (Trad. Castellana, 1997).

Levinas, Emmanuel. De otro modo que ser o más allá de la esencia. Salamanca: Ediciones Sígueme, 2003.

Níkleva, Dimitrinka. "Educación para la convivencia intercultural". Arbor 188.757 (2012): 991-999.

PNUD. Informe sobre desarrollo humano 2004: La libertad cultural en el mundo diverso de hoy, 2004. [Acceso 25 de enero de 2018]. Disponible en: http://hdr.undp.org/sites/default/files/ hdr_2004_es.pdf

Rivera Cusicanqui, Silvia. "Violencia e interculturalidad. Paradojas de la etnicidad de la Bolivia de hoy". Telar 15, San Miguel de Tucumán, 2015a.

Rivera Cusicanqui, Silvia. Sociología de la imagen, Miradas ch'ixi desde la historia andina. Argentina: Tinta Limón, 2015b.

Salas, Ricardo. "Antonio Sidekum y Raúl Fornet-Betancourt: Ética, reconocimiento y discurso intercultural". Utopía y Praxis Latinoamericana 18.60 (2013): 41-55.

Tubino, Fidel. "Del interculturalismo funcionalSan Salvador, iciembre de 2017.e E.63.3.ctividad y dinamismoavanzan deconstruyendo y reviviendo crso admite como indio y entonce", 2018a. Lima: PUCV. [Acceso 25 de enero de 2018]. Disponible en: http://red.pucp.edu.pe/wp-content/uploads/biblioteca/inter_funcional.pdf .

Tubino, Fidel. (2018b). "La impostergable alteridad: del conflicto a la convivencia intercultural", 2018b. [Acceso 25 de enero de 2018]. Disponible en: http://red.pucp.edu.pe/wp-content/ uploads/biblioteca/alteridad_ftubino.pdf

Van Cott, D. L. The Friendly Liquidation of the Past: the Politics of Diversity in Latin America. Pittsburgh: University of Pittsburgh Press, 2000. 
Walsh, Catherine. "(De) Construir la interculturalidad. Consideraciones críticas desde la política, la colonialidad y los movimientos indígenas y negros en el Ecuador". Interculturalidad y política. Desafíos y posibilidades. N. Fuller (ed.). Lima: Red para el desarrollo de las Ciencias Sociales en el Perú, 2002, 115-139. Disponible en: https://www.uasb.edu.ec/UserFiles/372/File/PonenciaLimal.pdf

Walsh, Catherine. (2009). "Interculturalidad crítica y educación intercultural". [Acceso 10 de mayo de 2020]. Disponible en: https://www.uchile.cl/documentos/interculturalidad-critica-y-educacion-intercultural_150569_4_1923.pdf

Zizek, Slavoj. "Multiculturalism, or, the Cultural Logic of Multinational Capitalism", en New Left Review 225 (1997): 29-49.

Zuchel, Lorena. Teología e interculturalidad, un kairós. Si estos callan, las piedras gritarán (Lucas 19,40). Ensayos de teología práctica interdisciplinar P. Achondo y P. Álvarez (ed.). Santiago de Chile: LOM, 2017a. 35-49.

Zuchel, Lorena. "Desde la retórica a la interculturalidad. Algunas reflexiones desde las aportaciones de Bartolomé de las Casas". Pensamiento 73.278 (2017b): 1151-171.

Zuchel, L. y Samour, H. "Conceptos filosóficos para una interculturalidad crítica. Aportes desde la filosofía del reconocimiento de Raúl Fornet Betancourt y de la filosofía de la realidad histórica de Ignacio Ellacuría". Hybris. Inédito, 2018. 